\title{
CLINICAL, EPIDEMIOLOGIC, AND ENDOSCOPIC PROFILE IN CHILDREN AND ADOLESCENTS WITH COLONIC POLYPS IN TWO REFERENCE CENTERS
}

\author{
Denise 0 ANDRADE ${ }^{1}$, Alexandre Rodrigues FERREIRA ${ }^{1}$, \\ Paulo Fernando S BITTENCOURT ${ }^{1}$, Daniela F P RIBEIRO' ${ }^{1}$, Rodrigo Gomes da SILVA ${ }^{1}$ \\ and Luiz Ronaldo ALBERTI
}

\begin{abstract}
Background - The main goal of this paper is to investigate the frequency, clinical profile, and endoscopic findings of children and teenagers submitted to colonoscopies. Methods - Patients of below 18 years of age, diagnosed with polyps by means of colonoscopies at two reference centers of pediatric endoscopy were followed-up between 2002 and 2012. The clinical variables evaluated in this study included: gender, recommendation of colonoscopy, associated signs and symptoms, age of onset of symptoms, age at identification of the polyp, interval of time between the onset of symptoms and the endoscopic diagnosis of colonic polyps, and family history of intestinal polyposis and/or colorectal cancer. The characteristics of the polyps also included: number, morphological type, histology, and distribution. Polyposis syndromes were also investigated. Results - From the 233 patients submitted to colonoscopies, polyps were found in $74(31.7 \%)$ patients, with a median age of 6.6 years, of which $61 \%$ were male. Juvenile polyps were identified in $55(74 \%)$ patients, with $7(9 \%)$ characterized within the criteria for juvenile polyposis. Patients with intestinal polyposis syndromes were diagnosed in $35 \%$ of the patients. The most frequent clinical presentation was hematochezia. Abdominal pain with acute episodes of intestinal partial obstruction or intussusception with emergency laparotomy was observed in the majority of Peutz-Jeghers syndrome patients leading to an increased morbidity. Conclusions - Even though juvenile colonic polyps are the most frequent type of diagnosed polyps, the present study identified a significant level of children with polyposis syndromes $(35 \%)$, associated with a higher morbidity of these individuals.
\end{abstract}

HEADINGS - Colonic polyps. Child. Adenomatous polyposis. Peutz-Jeghers syndrome. Colonoscopy.

\section{INTRODUCTION}

Gastrointestinal polyps are frequent in children and adolescentes, given that, historically, the majority are considered solitary, located in the rectosigmoid colon, presenting a juvenile hamartomatous histology with a minimal risk of developing into a malignant tumor $^{(1)}$. However, with the progress in endoscopic techniques, a change in the comprehension of colonic polyps has occurred. The application of the pancolonoscopy has demonstrated that, though the colonic polyps can more commonly be found in the rectosigmoid colon, these can also be found along the entire large intestine; multiple, with the possibility of recurrence in some children; and associated with premalign alterations ${ }^{(26)}$.
Reports in prior literature describe the occurrence of multiple polyps in $20 \%-50 \%$ of the children submitted to a colonoscopy with polypectomy ${ }^{(3,9,14,15,22-24,26)}$, in which $10 \%-50 \%$ of the polyps can be found near the sigmoid colon $^{(17,23,27,31)}$, while 3\%-15\% can be found exclusively in the right colon (including the transverse colon, the ascending colon, and the cecum) ${ }^{(3,9,17)}$. Children with multiple juvenile polyps, especially those with Juvenile Polyposis syndrome (JPS), can develop adenomatous transformations or even carcinomas in situ in the juvenile polyp in $26 \%-47 \%$ of the patients ${ }^{(5,15,23)}$. The coexistence of adenomas and adenocarcinomas, in addition to juvenile polyps can be found in $2 \%-15 \%$ of the cases. Moreover, the pediatrician must be aware that these polyps can occur in the context of hereditary polyposis syndromes, which present significant morbidity in this

Declared conflict of interest of all authors: none

Disclosure of funding: Fundação de Amparo à Pesquisa do estado de Minas Gerais - FAPEMIG

Departamento de Pediatria, Universidade Federal de Minas Gerais, Belo Horizonte, MG: ${ }^{2}$ Departamento de Cirurgia, Universidade Federal de Minas Gerais, Belo Horizonte, MG, Brasil.

Correspondence: Prof. Luiz Ronaldo Alberti. Departamento de Cirurgia, Universidade Federal de Minas Gerais. Av. Prof. Alfredo Balena, 190 - Santa Efigênia - CEP 30130-000 - Belo Horizonte, MG, Brasil. E-mail: luizronaldoa@yahoo.com.br 
age range, in addition to the increased risk of colorectal cancer and various types of cancer in other organs. Thus, flaws in the correct evaluation of these patients can lead to improper treatment. In this context, the absence of screening and check-ups on the part of at-risk individuals can lead to a diminishing of one's quality of life and early death.

Few studies can be found in literature regarding pediatric case series on polyps and intestinal polyposis. The present study aims to determine frequency, clinical characteristics, and colonoscopic findings in children and adolescents submitted to colonoscopies at two references centers in Gastroenterology and Pediatric Endoscopy in the city of Belo Horizonte, Brazil.

\section{METHODS}

This study was carried out in accordance with recommendations from the Declaration of Helsinki and the Resolution 196/96 from the Brazilian Ministry of Health concerning research involving human beings, and was approved by the Research and Ethics Committees from the Hospital Foundation of the State of Minas Gerais (protocol number 016$\mathrm{B} / 2010$ ) and from the Federal University of Minas Gerais (UFMG) (CAAE Project- 01882612.3.1001.5149).

This paper is a descriptive study of children and adolescents of up to 18 years of age who have been diagnosed with colonic polyps, identified though colonscopy and in medical procedures carried out in the Pediatric Endoscopy Services of the João Paulo II Children's Hospital from the Hospital Foundation of the State of Minas Gerais and the Alfa Institute of Gastroenterology from the UFMG Clinical Hospital, during the period of January 2002 to December 2012.

The data were retrieved from patient medical records, registries of endoscopic and histological reports, as well as interviews with the families during doctor's appointments or by telephone contact with the parents or responsible guardians. Patients diagnosed with pseudopolyps caused by intestinal inflammatory disease or polyps of infectious etiology, as well as those whose medical procedures and search for data were incomplete were excluded.

The clinical variables evaluated in this study included: gender, indication for the procedure, associated signs and symptoms, age of onset of symptoms, age at identification of the polyp, interval of time between the onset of symptoms and the endoscopic diagnosis of colonic polyps, and family history of intestinal polyposis and/or colorectal cancer (CRC).

Regarding the characteristics of the polyps, this study described: the number of polyps viewed by colonoscopy, morphological (sessile/pediculated) and histological types, and distribution along the large intestine. The anatomic distribution of the polyps was recorded as rectal, sigmoid, descending colon, left colon (when located up to the splenic flexure, with no specification of the location), right colon (when located proximal to the splenic flexure, with no specification of the location), transverse colon, ascending colon and cecum, pancolonic if located both proximally and distally to the splenic flexure, and ileum. The juvenile hamartomatous polyps were categorized as solitary and multiple (between two and five polyps). The Juvenile Polyposis syndrome (JPS) was defined by the presence of at least one of the following characteristics: more than five colorectal juvenile hamartomatous polyps, the presence of these polyps along the gastrointestinal tract, and the presence of any number of colorectal juvenile polyps associated with a family history of juvenile polyposis. The Peutz-Jeghers syndrome (PJS) was defined by the presence of one of the following criteria: two or more polyps confirmed histologically (hamartomatous-type polyp with an extension branching from the smooth muscles throughout the polyp); any number of typical polyps from the PJS confirmed histologically in an individual with a positive family history of PJS (first-degree relatives), mucocutaneous pigmentations that are characteristic of an individual with a positive family history of PJS (first-degree relatives), any number of histologically confirmed polyps from the PJS in an individual who presents characteristic mucocutaneous pigmentations. The Familial Adenomatous Polyposis (FAP) Syndrome was defined by the presence of multiple adenomatous colorectal polyps despite its size and location throughout the large bowel.

The data banks were created in the SPSS for Windows program. The descriptive analysis, including the average, median, standard deviation, interquartile range, and percentages, was used to characterize the studied group. The continuous variables with no normal distribution were expressed through medians and an interquartile range of 25\%-75\% (IQ25-75\%). The continuous variables with normal distribution were expressed through averages and standard deviation. Differences were considered significant for values corresponding to $P<0.05$.

\section{RESULTS}

During the period of the study, 233 patients were submitted to colonoscopies and $74(31.7 \%)$ children and adolescents were diagnosed with colorectal polyps. Patients with no polyps were submitted to only one colonoscopy. Among a total of 158 colonoscopies and 537 polypectomies carried out in 74 children diagnosed with polyps (non-inflammatory or infectious), complications were found in one patient, who had undergone a polypectomy, with a possible perforation. In this case, endoscopic therapy was successful with the use of an endoclip and antibiotics.

The age of the patients when diagnosed with a polyp presented a median of 6.6 years (IQ25-75\% - 3.9-10.7 years); $45(61 \%)$ of the patients were male.

Juvenile, solitary and multiple polyps were identified in $48 / 74(65 \%)$ patients, with $42 / 74(57 \%)$ diagnosed with solitary juvenile polyps and 6/74 (8\%) with multiple juvenile polyps (Table 1). In this study, 26/74 (35\%) of the patients were diagnosed with polyposis syndromes (Table 2). The distribution of polyps along the large intestine is shown in Figure 1. 
A predominance of larger and pediculated polyps could be observed in patients with solitary juvenile polyps, occurring most commonly in younger patients, as compared to those with polyposis/multiple polyps (Table 3).

PJS was found in six patients. The clinical characteristics and treatment of these patients is summarized in Tables 2 and 3 . Three patients $(50 \%)$ were submitted to emergency laparotomy due to intestinal intussusception. The histological evaluation of the dry colonic polyps identified both Peutz-Jeghers hamartomatous polyps and hyperplasic polyps. The gastric polyps presented a varied topographic distribution and a predominance of the hyperplasic type when submitted to histology (Figure 1). All of the polyps resected by enteroscopy presented a typically Peutz-Jeghers type of hamartomatous histology.

Of the 13 patients diagnosed with adenomatous polyposis, all presented a positive family history, 6 of which were from two families; 12 presented adenomas in the first colonoscopy. Colonic cancer was found in a 15.7 years old patient, concomitantly with the diagnosis of polyposis syndrome.

TABLE 1. Clinical and endoscopic characteristics of the patients with juvenile polyps

\begin{tabular}{|c|c|c|c|c|}
\hline & TOTAL JP & SJP & MJP & PJS \\
\hline Total number of patients & $55(100)$ & $42(76 \%)$ & $6(11 \%)$ & $7(13 \%)$ \\
\hline Positive & $7(13)$ & $3(7)$ & 0 & $4(57)$ \\
\hline Hematochezia & $53(96)$ & $40(95)$ & $6(100)$ & $7(100)$ \\
\hline Abdominal pain & $10(18)$ & $8(19)$ & 0 & $1(14)$ \\
\hline Prolapse of anal polyp & $11(20)$ & $7(17)$ & $3(50)$ & $1(14)$ \\
\hline Median (IQ 25\%-75\%) & $4.4(2.6-6.7)$ & $4.1(2.5-6.8)$ & $4.3(2.9-5.1)$ & $4.7(2.9-5.2)$ \\
\hline Time of evolution of symptoms (months) & 1 to 60 & 1 to 60 & 2 to 24 & 6 to 36 \\
\hline Median (IQ 25\%-75\%) & $7.5(4-12)$ & $6(3-12)$ & $10(7.3-21)$ & \\
\hline Age upon diagnosis (years) & $1.5-16.8$ & $1.5-16.8$ & $3.3-8.1$ & $3.6-8.1$ \\
\hline Median (IQ 25\%-75\%) & $5.4(3.5-7.8)$ & $4.9(3.3-8.6)$ & $5.9(5.3-6.2)$ & $6.0(5.2-6.4)$ \\
\hline Alterations to the physical exam $\mathrm{N}(\%)$ & 0 & 0 & 0 & 0 \\
\hline Pediculated & 34 & 30 & 4 & 0 \\
\hline Sessile + Pediculated & 9 & 0 & 2 & 7 \\
\hline Indefinite & 6 & 6 & 0 & 0 \\
\hline
\end{tabular}

SJP: solitary juvenile polyp; MJP: multiple juvenile polyp; PJS: Peutz Jeguers syndrome; N: number of patients. 
TABLE 2. Clinical and endoscopic characteristics of patients with polyposis

\begin{tabular}{|c|c|c|c|c|}
\hline & SJP & PJS & PAF & All polyposis \\
\hline Male & $5(71)$ & $4(67)$ & $6(46)$ & $15(58)$ \\
\hline Male:Female & $2.5: 1.0$ & 2.0:1.0 & 1.0:1.0 & $1.4: 1.0$ \\
\hline $\begin{array}{l}\text { Positive family history - (polyposis/colorretal } \\
\text { carcinoma) N }(\%) \text { : }\end{array}$ & $4(57)$ & $5(83)$ & $13(100)$ & $22(85)$ \\
\hline \multicolumn{5}{|l|}{ Reason for colonoscopy $\mathrm{N}(\%)$ : } \\
\hline Screening & 0 & $1(17)$ & $9(69)$ & $10(38)$ \\
\hline \multicolumn{5}{|l|}{ Clinical alterations: } \\
\hline Total & $7(100)$ & $5(83)$ & $4(31)$ & $16(62)$ \\
\hline Prolapse of anal polyp & $1(14)$ & 0 & 0 & $1(4)$ \\
\hline Intestinal Invagination & 0 & $3(50)$ & 0 & $3(12)$ \\
\hline Diarrhea & $1(14)$ & 0 & $2(16)$ & $3(12)$ \\
\hline Time of symptoms (months) & 6 to 48 & 2 to 132 & 2 to 48 & 2 to 48 \\
\hline Median (IQ 25\%-75\%) & $24(18-24)$ & $27.5(5.8-69)$ & $2.5(2-7)$ & $18(5.1-39)$ \\
\hline Age of onset of symptoms (years) & $2.4-5.8$ & $3-13.1$ & $8.9-18.2$ & $2.5-18.0$ \\
\hline Median (IQ 25\%-75\%) & $4.7(2.9-5.2)$ & $9.0(8.0-12.5)$ & $13.5(10.5-14.7)$ & $6.5(3.0-12.5)$ \\
\hline \multicolumn{5}{|l|}{ With alterations: } \\
\hline Total & 0 & $6(100)$ & $3(23)$ & $9(35)$ \\
\hline Mucocutaneous Hiperpigmentation & 0 & $6(100)$ & 0 & $6(23)$ \\
\hline ADNPM & 0 & 0 & $1(8)$ & $1(4)$ \\
\hline Nodules s.c. (lipomas, sebaceous cystos) & 0 & 0 & $3(23)$ & $3(12)$ \\
\hline Osteomas & 0 & 0 & $1(8)$ & $1(4)$ \\
\hline Number of polyps $\mathrm{N}(\%)$ & $6(2) ;>10(5)$ & $1(1) ; 11(1) ; 12(1) ; 6(1)$ & $>100(11) ;<50(2)$ & $1->100$ \\
\hline Size fo polyps (mm) & $3-25$ & $5-25$ & $1-10$ & $1-25$ \\
\hline Median (IQ 25\%-75\%) & $6.5(3.3-13.8)$ & $6(5-15)$ & $3.0(2.5-5.0)$ & $5(3-7.3)$ \\
\hline Morphology of polyps (S/P/S + P/I) & $0 / 0 / 7 / 0$ & $2 / 0 / 2 / 0$ & $10 / 0 / 3 / 0$ & $12 / 0 / 12 / 0$ \\
\hline
\end{tabular}

SJP: solitary juvenile polyp; PJS: Peutz-Jeghers syndrome; FAP: familial adenomatous polyposis; N: number of patients; DNPMD: delay in neuro-psychomotor development; E: sessile; P: pediculated; I: indiscriminate. 
FIGURE 1. Patients and distribution of polyps according to topography

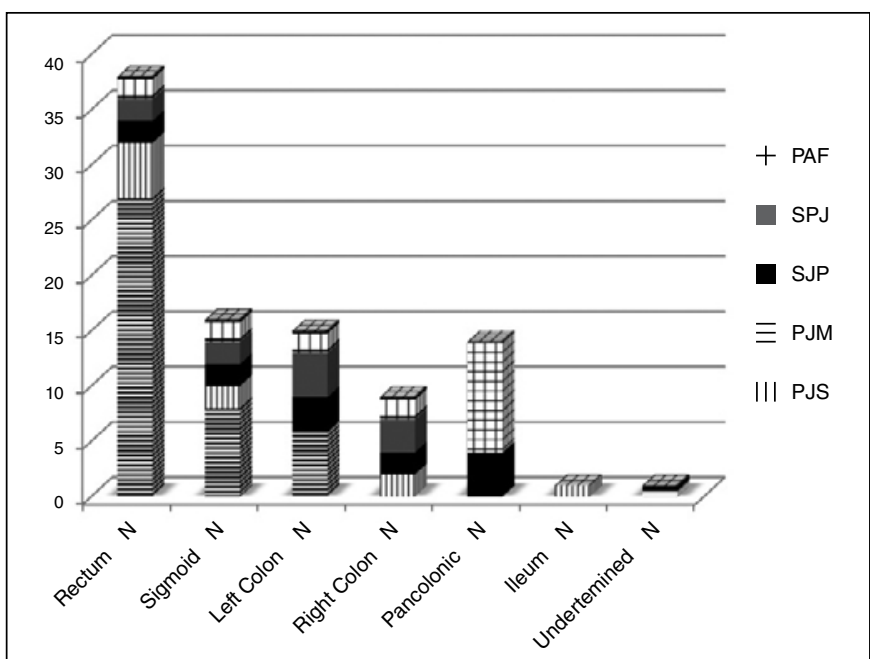

SPJ: solitary juvenile polyp; PJM: multiple juvenile polyp; SJP: polyposis juvenile syndrome; PJS: Peutz-Jeghers syndrome; FAP: familial adenomatous polyposis.

TABLE 3. Comparison of patients with solitary juvenile polyps and the others (multiple juvenile polyps and polyposis)

\begin{tabular}{lcc}
\hline & SJP & Non SJP \\
\hline Age of onset of symptoms (years) & $0.8-12$ & $2.2-18.2$ \\
Median (IQ 25\%-75\%) & $4.2(2.8-6.2)$ & $6.2(4.5-12.4)$ \\
Age upon diagnosis (years) & $1.5-16.8$ & $3.7-18.7$ \\
Median (IQ 25\%-75\%) & $4.9(3.3-8.6)$ & $11.3(6.7-11.5)$ \\
Size of polyps (mm) & $4-40 \mathrm{MM}$ & $1-25 \mathrm{MM}$ \\
Median (IQ 25\%-75\%) & $15(9-20)$ & $5(3-10)$ \\
Morphology of polyps (N) & & \\
Sessile & 6 & 13 \\
Pediculated & 31 & 4 \\
Sessile + Pediculated & 0 & 3 \\
Indiscriminate & 6 & 11 \\
\hline
\end{tabular}

SJP: solitary juvenile polyp; MJP: multiple juvenile polyp; PJS: polyposis juvenile syndrome; $\mathrm{N}$ : number of patients.

\section{DISCUSSION}

Gastrointestinal polyps are common in the pediatric age group, with lesions presenting juvenile harmatomatous histology identified in $88 \%-100 \%$ of the polyps removed by colonscopy $^{(3,9,24,30)}$. The polyposis syndromes are quite rare, varying between $12 \%$ and $17 \% \%^{(14,19,21)}$, while the JPS is predominant in the majority of pediatric cases ${ }^{(9,19,21,30)}$. The greater prevalence in this paper is due to the fact that the two centers where the exams were carried out are reference centers for the treatment of complex pediatric diseases. The predominance of males in this series $(61 \%)$ is in accordance with the majority of prior publications ${ }^{(14,17,21,25,26)}$, with the tendency of solitary juvenile polyps occurring at earlier ages as compared to children with multiple polyps or juvenile polyposis ${ }^{(9,17,19,21,24,26,32)}$.

It could be observed that the majority of children with juvenile polyps, presented hematochezia associated or not with other symptoms, including the prolapse of the rectal mucous membrane or an anal polyp, abdominal pain, and diarrhea, which is similar to findings from other pediatric case series ${ }^{(9,31)}$. This study identified no signs of protein-losing enteropathy, which commonly presents a worse prognosis and mortality at early ages, generally in children of less than five years of age ${ }^{(33)}$.

In the majority of patients with JPS, the first symptoms and complications appear in the first two decades of life $\mathrm{e}^{(8,34,37)}$. Abdominal pain associated or not with an acute obstructive condition is the most common symptom and was present in $93 \%-100 \%$ of the patients, with one case reported in the neonatal period ${ }^{(6)}$. Utsunomiya et al. observed an acute obstructive condition of the abdomen in $43 \%$ of the patients ${ }^{(34)}$, which is similar to other case series ${ }^{(2,8,37)}$, and could also be observed in this sample. The mucocutaneous hyperpigmentation, present in $95 \%$ of the patients with $\mathrm{JPS}^{(13)}$, appears most commonly in the first two years of life, tapering off at puberty, with a tendency of disappearing in adulthood ${ }^{(34,37)}$. In the present study, one patient presented these symptoms as of the first month of life.

In the diagnosis of adenomatous polyps in this case series, the patients were asymptomatic in most cases and were submitted to a colonoscopy due to a family history of PAF, which is in accordance with findings reported in the literature ${ }^{(12,28)}$. Patients with PAF were asymptomatic within the pediatric age group, with only rare symptomatic cases before the second decade of life ${ }^{(10,11)}$, when the main manifestation appears as intermittent rectal bleeding, followed by abdominal pain, anemia, and diarrhea, which is similar to that found in the present case series. Benign extracolonic manifestations, such as congenital hypertrophy of the retina, epidermoid cysts, and osteomas, may also be present ${ }^{(15,35)}$, a fact also proven in the present case series. Desmoid tumors can be found in $10 \%-15 \%$ of the patients with $\mathrm{PAF}^{(4,18)}$. Although these are histologically benign lesions, they can be aggressive and difficult to cure, with significant morbidity and mortality rates.

Although the majority of polyps in children appeared in a distal location, the frequency of the proximal location varied from $5 \%-32 \%{ }^{(1,3,9,14,17,24,27,32)}$. In the present study, polyps located proximal do the splenic flexure was found in $35 \%$ of the cases.

In the JPS, the hamartomatous polyps, which are most common in the colorectal region, predominate, a fact which could be observed in this study, which are also associated with hyperplasic polyps. Hofting et al. ${ }^{(20)}$ reported the involvement of the large intestine in $98 \%$, the stomach in $14 \%$, the jejunum and ileum in $7 \%$, and the duodenum in $2 \%$ of the patients. In rare cases, these can also occur in an isolated form in the stomach in the absence of colonic polyposis ${ }^{(36)}$. The risk of cancer in patients with juvenile polyps, mainly in patients with multiple polyps, including the presence of adenomatous alterations in the juvenile polyp (26\%-47\%) and the coexistence of adenomas with no characteristics of the juvenile polyp 
or even of adenocarcinoma associated with the presence of juvenile polyp $(2 \%-15 \%)^{(15)}$, has been reported. In the group of patients with JPS in this study, no dysplastic alterations nor cases of adenomas or adenocarcinomas could be observed.

In the individuals with PJS, the polyps can be detected in $88 \%$ of the patients distributed along the entire digestive tract, with the exception of the esophagus ${ }^{(34)}$, located predominantly in the small intestine (65\%-97\%) and colon (50\%-64\%), and with a greater prevalence in the stomach (24\%-38\%), duodenum (37\%), and rectum $(32 \%)^{(2,8,23,34)}$. Other extra-intestinal sites, present in up to $5.5 \%$ of the patients, include the gallbladder, the respiratory tract, the urinary bladder, and the ureter ${ }^{(34)}$. In the present case series, hamartomatous polyps, which are typical of the syndrome, were detected in all of the patients in the colon, small intestine, and gastroduodenal topographies.

In patients with PAF, the classic phenotypical manifestation is that of innumerous adenomatous colonic polyps, which, by definition, are more than 100 , but can reach thousands, distributed along the entire gastrointestinal tract, commonly detected at an average age of $15^{(1)}$, reaching a $90 \%$ prevalence in patients of 40 years of age ${ }^{(1)}$. However, in $8 \%-15 \%$ of the patients, the syndrome can appear in a lighter form, with a smaller number of colonic adenomas. The present study observed that 13 patients presented innumerous adenomatous polyps (more than 100) in a pancolonic distribution, while two $(15 \%)$ patients presented a lighter phenotypical manifestation of the disease. All of the polyps were less than $1 \mathrm{~cm}$, with a median size of $3 \mathrm{~mm}$, with a tubular or tubular-villous histology, which was in accordance with the literature ${ }^{(1)}$.

The polyps can also develop in the upper gastrointestinal tract, being the fundic gland polyps in the stomach the most common, both in children and in adults ${ }^{(1)}$. The duodenum is the second most common location for the development of adenomas in patients with PAF, occurring in $90 \%-100 \%$ of the patients throughout their lifetimes ${ }^{(5,35)}$. The patients submitted to upper endoscopy in this case series presented gastroduodenal alterations, which was in accordance with prior reports.

The risk of malign transformation in a solitary juvenile polyp appears to be insignificant. Nugent, in a review of 82 patients with solitary juvenile polyp, observed no increased risk of cancer or greater mortality related to the poly $\mathrm{p}^{(29)}$. However, considerations regarding the risk of cancer in patients with juvenile polyps have been reported concerning those patients with multiple polyps, in which the presence of adenomatous alterations in the juvenile polyp ( $26 \%-47 \%$ of the patients with JPS), the coexistence of adenomas with no characteristics of juvenile polyps, or even of adenocarcinoma associated with the presence of juvenile polyps ( $2 \%-15 \%$ of the cases of JPS) have been reported ${ }^{(37)}$. Moreover, the patient must be aware that polyps can occasionally appear in the context of a hereditary polyposis disease characterized by significant morbidity in this age group and with an increased risk of cancer in the gastrointestinal tract and in other organs, especially in adulthood ${ }^{(16)}$.

Based on these data, the majority of specialists currently recommend an initial investigation with a complete colonoscopy in all children suspected of having colonic polyps. All polyps should be removed and submitted to histological studies. Upon obtaining the endoscopic and histological data (number, distribution, and histological type), associated with the information relevant to the family history of polyposis and/or CCR, as well as the clinical history of the patient, the doctor can make more precise decisions concerning the therapy and follow-up to for the patients and at-risk family members.

\section{CONCLUSION}

Although the solitary juvenile colonic polyps are the most common, a significant percentage of children with polyposis syndromes $(35 \%)$, associated with a greater morbidity could be observed. In this light, the establishment of diagnostic protocols and effective follow-up treatment with affected patients and at-risk family members is of utmost importance.

\section{ACKNOWLEDGEMENTS}

The authors gratefully acknowledge the Foundation for the Assistance to Research of Minas Gerais State (FAPEMIG) for financial support.

\section{Authors' contributions}

Andrade DO: literature review, endoscopic procedures. Ferreira AR: experiment design, execution of the clinical trial. Bittencourt PFS: endoscopic procedures, experimente design. Ribeiro DFP: survey data. Silva RG: survey data. Alberti LR: data analysis, preparation of the manuscript. 
Andrade DO, Ferreira AR, Bittencourt PFS, Ribeiro DFP, Silva RG, Alberti LR. Perfil clínico, epidemiológico e endoscópico em crianças e adolescentes com pólipos colônicos em dois centros de referência. Arq Gastroenterol. 2015,52(4):xxx.

RESUMO - Objetivos - Conhecer a frequência, o perfil clínico, os achados endoscópicos, de crianças e adolescentes submetidos à colonoscopia em dois centros de referência em gastroenterologia e endoscopia pediátrica. Métodos - Foram avaliados e acompanhados pacientes com idade menor ou igual a 18 anos com diagnóstico de pólipos identificados à colonoscopia em dois centros de referência em endoscopia pediátrica no período de 2002 a 2012 . As variáveis clínicas avaliadas foram: gênero, indicação da colonoscopia, sinais e sintomas associados, idade de início dos sintomas, idade à identificação do pólipo, intervalo de tempo entre início dos sintomas e diagnóstico endoscópico do pólipo colônico, história familiar de polipose intestinal e/ou câncer coloretal. Em relação às características dos pólipos foram descritos: número, tipo morfológico, histológico e distribuição. Foram estudadas também as síndromes poliposas (síndrome de Peutz-Jeghers, síndrome juvenil poliposa, síndrome poliposa adenomatosa familiar). Resultados - Dos 233 pacientes submetidos à colonoscopia, foram encontrados 74 (31,7\%) pacientes com pólipos, com mediana de idade de 6,6 anos, $61 \%$ do gênero masculino. Pólipos juvenis foram identificados em 55 (74\%) dos pacientes, sendo 7 ( $9 \%$ ) com critérios diagnósticos de polipose juvenil. Pacientes com síndromes poliposas intestinais foram diagnosticados em 35\% dos pacientes. Destes, $12 \%$ com diagnóstico de polipose adenomatosa familiar, $9 \%$ com síndrome juvenil poliposa e 8\% com diagnóstico de Síndrome de Peutz-Jeghers. A apresentação clínica mais frequente foi o sangramento retal indolor. Nos pacientes com polipose adenomatosa familiar o principal motivo da indicação da colonoscopia foi para rastreamento da doença devido história familiar da síndrome poliposa. Um paciente apresentou adenocarcinomacoloretal, simultâneo ao diagnóstico da polipose adenomatosa aos 15 anos de idade. Dor abdominal com episódios agudos de semiobstrução ou intussuscepção intestinal com laparotomia de urgência foi observado nos pacientes com Peutz-Jeghers. Conclusões - Embora os pólipos colônicos juvenis sejam os mais frequentemente diagnosticados, foi observado um percentual significativo de crianças com síndromes poliposas (35\%) associado a uma maior morbidade destas crianças. Desta forma concluímos ser importante estabelecimento de um protocolo de diagnóstico e seguimento dos pacientes afetados e familiares de risco.

DESCRITORES - Pólipos do colo. Criança. Polipose adenomatosa. Síndrome de Peutz-Jeghers. Colonoscopia.

\section{REFERENCES}

1. Attard TM, Cuffari C, Tajouri T, Stoner JA, Eisenberg MT, Yardley JH, et al. Multicenter experience with upper gastrointestinal polyps in pediatric patients with familial adenomatous polyposis. Am J Gastroenterol. 2004;99(4):681-6.

2. Bartholomew LG, Moore CE, Dahlin DC, Waugh JM. Intestinal polyposis associated with mucocutaneous pigmentation. Surg Gynecol Obstet. 1962;115:111.

3. Bartnik W, Butruk E, Ryzko J, Rondio H, Rasinski A, Orlowska J. Short- and long-term results of colonoscopic polypectomy in children. Gastrointest Endosc. Dec. 1986;32(6):389-92.

4. Bertario L, Russo A, Sala P, et al. Genotype and phenotype factors as determinants of desmoid tumors in patients with familial adenomatous polyposis. Int $\mathrm{J}$ Cancer. 2001;95(2):102-7.

5. Bulow S, Bjork J, Christensen IJ, et al. Duodenal adenomatosis in familial adenomatous polyposis. Gut. 2004;53(3):381-6.

6. Burgmeier C, Schier F, Staatz G. Gastric outlet obstruction in a neonate because of Peutz-Jeghers syndrome. J Pediatr Surg. 2012;47(8):e1-3.

7. Campos FG, Habr-Gama A, Kiss DR, Atui FC, Katayama F, Gama-Rodrigues J. [Extracolonic manifestations of familial adenomatous polyposis: incidence and impact on the disease outcome]. Arq Gastroenterol. 2003;40(2):92-8.

8. Choi HS, Park YJ, Youk EG, et al. Clinical characteristics of Peutz-Jeghers syndrome in Korean polyposis patients. Int J Colorectal Dis. 2000;15(1):35-8.
9. Cynamon HA, Milov DE, Andres JM. Diagnosis and management of colonic polyps in children. J Pediatr. 1989;114(4 Pt 1):593-6.

10. Dukes CE. Cancer control in familial polyposis of the colon. Dis Colon Rectum. 1958;1(6):413-23.

11. Dukes CE. Familial intestinal polyposis. Ann Eugen. 1952;17(Part 1):1-29.

12. Durno CA. Colonic polyps in children and adolescents. Can J Gastroenterol. 2007;21(4):233-9.

13. Fernandez Seara MJ, Martinez Soto MI, Fernandez Lorenzo JR, Trabazo S, Gamborino E, Forteza Vila J. Peutz-Jeghers syndrome in a neonate. J Pediatr. 1995;126(6):965-7.

14. Fox VL, Perros S, Jiang H, Goldsmith JD. Juvenile polyps: recurrence in patients with multiple and solitary polyps. Clin Gastroenterol Hepatol. 2010;8(9):795-9.

15. Giardiello FM, Hamilton SR, Kern SE, et al. Colorectal neoplasia in juvenile polyposis or juvenile polyps. Arch Dis Child. 1991;66(8):971-5.

16. Giardiello FM, Offerhaus GJ, Traboulsi EI, et al. Value of combined phenotypic markers in identifying inheritance of familial adenomatous polyposis. Gut. 1991;32(10):1170-4.

17. Gupta SK, Fitzgerald JF, Croffie JM, et al. Experience with juvenile polyps in North American children: the need for pancolonoscopy. Am J Gastroenterol. 2001;96(6):1695-7.

18. Gurbuz AK, Giardiello FM, Petersen GM, et al. Desmoid tumours in familial adenomatous polyposis. Gut. 1994;35(3):377-81.

19. Hoffenberg EJ, Sauaia A, Maltzman T, Knoll K, Ahnen DJ. Symptomatic colonic polyps in childhood: not so benign. J Pediatr Gastroenterol Nutr. 1999;28(2):175-81. 
20. Hofting I, Pott G, Stolte M. [The syndrome of juvenile polyposis]. Leber Magen Darm. 1993;23(3):107-8, 111-102

21. Hood B, Bigler S, Bishop P, et al. Juvenile polyps and juvenile polyp syndromes in children: a clinical and endoscopic survey. Clin Pediatr (Phila). 2011;50(10):910-5.

22. Hueting WE, Buskens E, van der Tweel I, Gooszen HG, van Laarhoven CJ Results and complications after ileal pouch anal anastomosis: a meta-analysis of 43 observational studies comprising 9,317 patients. Dig Surg. 2005;22(1-2):69-79.

23. Hyer W, Beveridge I, Domizio P, Phillips R. Clinical management and genetics of gastrointestinal polyps in children. J Pediatr Gastroenterol Nutr. 2000;31(5):469-79.

24. Jalihal A, Misra SP, Arvind AS, Kamath PS. Colonoscopic polypectomy in children. J Pediatr Surg. 1992;27(9):1220-2.

25. Ko FY, Wu TC, Hwang B. Intestinal polyps in children and adolescents--a review of 103 cases. Zhonghua Min Guo Xiao Er Ke Yi Xue Hui Za Zhi. 1995;36(3):197202.

26. Mestre JR. The changing pattern of juvenile polyps. Am J Gastroenterol. 1986;81(5):312-4

27. Mougenot JF, Baldassarre ME, Mashako LM, Hanteclair GC, Dupont C, Leluyer B. [Recto-colic polyps in the child. Analysis of 183 cases]. Arch Fr Pediatr. 1989;46(4):245-8.

28. Munck A, Gargouri L, Alberti C, et al. Evaluation of guidelines for management of familial adenomatous polyposis in a multicenter pediatric cohort. J Pediatr Gastroenterol Nutr. 2011;53(3):296-302.
29. Nugent KP, Spigelman AD, Phillips RK. Life expectancy after colectomy and ileorectal anastomosis for familial adenomatous polyposis. Dis Colon Rectum. 1993;36(11):1059-62.

30. Perisic VN. Colorectal polyps: an important cause of rectal bleeding. Arch Dis Child. 1987;62(2):188-9.

31. Pillai RB, Tolia V. Colonic polyps in children: frequently multiple and recurrent. Clin Pediatr (Phila). 1998;37(4):253-7.

32. Poddar U, Thapa BR, Vaiphei K, Singh K. Colonic polyps: experience of 236 Indian children. Am J Gastroenterol. 1998;93(4):619-22.

33. Sachatello CR, Griffen WO, Jr. Hereditary polypoid diseases of the gastrointestinal tract: a working classification. Am J Surg. 1975;129(2):198-203.

34. Utsunomiya J, Gocho H, Miyanaga T, Hamaguchi E, Kashimure A. PeutzJeghers syndrome: its natural course and management. Johns Hopkins Med J. 1975; 136(2):71-82

35. Valanzano R, Cama A, Volpe R, et al. Congenital hypertrophy of the retinal pigment epithelium in familial adenomatous polyposis. Novel criteria of assessment and correlations with constitutional adenomatous polyposis coli gene mutations. Cancer. 1996;78(11):2400-10.

36. Watanabe A, Nagashima H, Motoi M, Ogawa K. Familial juvenile polyposis of the stomach. Gastroenterology. 1979;77(1):148-51

37. Westerman AM, Entius MM, de Baar E, et al. Peutz-Jeghers syndrome: 78-year follow-up of the original family. Lancet. 1999;353(9160):1211-5. 